\title{
Characterization of drug resistance associated genetic polymorphisms among Plasmodium falciparum field isolates in Ujjain, Madhya Pradesh, India
}

Ashish Pathak ${ }^{1,2,3}$, Andreas Mårtensson 3,4,7, Sudhir Gawariker ${ }^{5}$, Jagdish Mandliya' ${ }^{1}$, Ashish Sharma ${ }^{5}$, Vishal Diwan ${ }^{3,6}$ and Johan Ursing ${ }^{4^{*}}$

\begin{abstract}
Background: Since 2011, artesunate + sulphadoxine-pyrimethamine (ASP), instead of chloroquine, has been recommended for treatment of uncomplicated malaria in India. In Ujjain, central India, with an annual parasite index $<0.1$, the prevalence of drug-resistant Plasmodium falciparum is unknown. In other parts of India chloroquine and sulphadoxine-pyrimethamine-resistant $P$. falciparum is prevalent. The aim of this study was to determine the prevalence of anti-malarial drug resistance-associated genetic polymorphisms in $P$. falciparum collected in Ujjain in 2009 and 2010, prior to the introduction of ASP.

Methods: Blood samples from 87 patients with $P$. falciparum mono-infection verified by microscopy were collected on filter-paper at all nine major pathology laboratories in Ujjain city. Codons Pfcrt 72-76, pfmdr1 1034-1246, pfdhfr 16-185, pfdhps 436-632 and pfnhe1 ms4760 haplotypes were identified by sequencing. Pfcrt K76T and pfmdr1 N86Y were identified by restriction fragment length polymorphism, and pfmdr 1 gene copy number by real-time PCR.

Results: Sulphadoxine-pyrimethamine resistance-associated pfdhfr $108 \mathrm{~N}$ and 59R alleles were found in 75/78 (96\%) and 70/78 (90\%) samples, respectively, and pfdhps $437 \mathrm{G}$ was found in 7/77 (9\%) samples. Double mutant pfdhfr $59 R+108 \mathrm{~N}$ were found in 62/76 (82\%) samples. Triple mutant pfdhfr 59R $+108 \mathrm{~N}$ and pfdhps $437 \mathrm{G}$ were found in 6/76 (8\%) samples. Chloroquine-resistance-associated pfcrt $76 \mathrm{~T}$ was found in 82/87 (94\%). The pfcrt 72-76 haplotypes found were: 80/84 (95\%) SVMNT, 3/84 (4\%) CVMNK and 1/84 (1\%) CVMNT. Pfmdr1 N86 and 86Y were identified in 70/83 (84\%) and 13/83 (16\%) samples, respectively. Pfmdr1 S1034 + N1042 + D1246 were identified together in 70/72 (97\%) of successfully sequenced samples. One pfmdr1 gene copy was found in 74/75 (99\%) successfully amplified samples.

Conclusion: This is the first characterization of key anti-malarial drug resistance-associated genetic markers among P. falciparum collected in Ujjain, Madhya Pradesh, India. The results indicate that the efficacy of standard dose chloroquine at the time of the study was likely to be poor, whereas ASP was likely to be efficacious, supporting the changed drug treatment policy. However, $P$. falciparum with reduced susceptibility to sulphadoxine-pyrimethamine is highly prevalent, highlighting the need for continuous surveillance of ASP efficacy in the study area.
\end{abstract}

Keywords: Plasmodium falciparum, Artesunate sulphadoxine-pyrimethamine, Chloroquine, Resistance, pfcrt, pfmdr 1, pfdhfr, pfdhps, pfnher

\footnotetext{
* Correspondence: johan.ursing@karolinska.se

${ }^{4}$ Malaria Research, Department of Medicine Solna, Karolinska Institutet,

Stockholm, Sweden

Full list of author information is available at the end of the article
} 


\section{Background}

Approximately $85 \%$ of India's population of 1.2 billion people live in malarious areas and transmission intensities vary from unstable to hyperendemic [1,2]. In 2012 there were 1.3 million reported malaria cases in India, although the true burden is probably considerably higher $[2,3]$. Furthermore, the proportion of the more virulent Plasmodium falciparum has increased in recent years and now accounts for $49 \%$ of the total malaria burden [2,4]. Since 2011 the Directorate of National Vector Born Disease Control Programme recommends that verified uncomplicated P. falciparum malaria and severe malaria should be treated with artesunate plus sulphadoxine-pyrimethmine (ASP) and quinine, respectively. Chloroquine (CQ) was the official first line drug prior to 2011. However, in areas with known CQ resistance, sulphadoxine-pyrimethmine (SP), between 1982 and 2005 and from 2005 ASP were recommended for treatment of uncomplicated malaria instead of CQ [4]. High grade SP resistance is widespread in parts of Southeast Asia and artemisinin resistance is developing along the Thai-Cambodia and Thai-Myanmar borders [5-7]. Furthermore, the PCR-corrected day 42 ASP failure rate was $9.5 \%(5 / 53)$ in a recent study from West Bengal [8]. There is thus a need to monitor AS-SP efficacy throughout India.

SP resistance in $P$. falciparum has been linked to single nucleotide polymorphisms (SNPs) A16V, C50R, N51I, C59R, S108N/T and I164L in dihydrofolate reductase (pfdhfr) and SNPs S436A/F, A437G, K540E, A581G and A613S in dihydropteroate synthase (pfdhps) [9-14]. Accumulation of SNPs typically starting with S108N leads to gradual reduction of susceptibility to SP and increased risk of treatment failure [15]. The quintuple pfdhfr $51 \mathrm{I}+59 \mathrm{R}+108 \mathrm{~N}$ and pfdhps $437 \mathrm{G}+540 \mathrm{E}$ haplotype is highly predictive of SP treatment failure in Africa [16]. In line with this, ASP treatment failures in West Bengal occurred in patients with pfdhfr $51 \mathrm{I}+59 \mathrm{R}+$ $108 \mathrm{~N}$ and pfdhps $437 \mathrm{G}$ or $436 \mathrm{~A}+540 \mathrm{E}$ [8]. These SNP combinations have also been reported from Odisha (eastern India) and the triple pfdhfr $59 \mathrm{R}+108 \mathrm{~N}+164 \mathrm{~L}$ haplotype has been reported from the northeastern state of Assam $[17,18]$. Moreover, quadruple pfdhfr $51 \mathrm{I}+59 \mathrm{R}+108 \mathrm{~N}+$ $164 \mathrm{~L}$ and pfdhps with three or four resistance-associated SNP combinations are common on the Andaman and Nicobar islands (Bay of Bengal) [19-21].

Resistance to CQ has developed in only five geographical locations but has spread from these points of origin to encompass most of the malaria endemic world $[7,22]$. A K76T SNP in the P. falciparum CQ resistance transporter gene $(p f c r t)$ is essential for CQ resistance and this has been found at high frequencies throughout India [23-27]. Typically $76 \mathrm{~T}$ is found together with additional SNPs creating specific pfcrt 72-76 haplotypes that indicate the origin of $\mathrm{CQ}$ resistance [22]. The pfcrt 72-76 haplotypes SVMNT from Papua
New Guinea and CVIET from Southeast Asia are predominant in India $[17,28]$.

In addition to these well-characterized, resistance-causing SNPs, $P$. falciparum multidrug resistance gene ( $p f m d r 1)$ and sodium/hydrogen exchanger gene (pfnhe1) have been associated with anti-malarial drug resistance: Pfmdr1 N86Y, S1034C, N1042D and D1246Y have been suggested to modulate levels of CQ resistance [29,30]. Increased $p f m d r 1$ copy number has been linked to reduced susceptibility to artemisinin derivatives, lumefantrine, piperaquine and mefloquine as well as artesunate + mefloquine treatment failure [31-34]. Pfmdr1 N86 and pfcrt K76 have been linked to reduced lumefantrine susceptibility [35-37]. Pfmdr1 S1034C, N1042D and D1246Y, >1 DNNND repeats and one DDNHNDNHNND repeat in the coding microsatellite ms 4760 of pfnhe1 have been linked to reduced quinine sensitivity $[29,38,39]$.

Monitoring the frequency of $P$. falciparum resistanceassociated genetic polymorphisms thus has the potential to identify declining susceptibility to a number of antimalarial drugs. In Ujjain district located in Madhya Pradesh, central India, CQ was used until 2011 when ASP was introduced but no data on drug susceptibility of $P$. falciparum in the area exists. This study therefore analysed key anti-malarial resistance-associated genetic markers prior to the introduction of ASP for the first time. The report provides baseline data indicating a probable high efficacy of ASP and facilitates future monitoring of changing prevalence of resistanceassociated genetic polymorphisms in this region as well as for comparisons with neighbouring areas.

\section{Methods}

\section{Study site and period}

Ujjain district is located in the western part of Madhya Pradesh, central India. The population of the district is 1.9 million as per 2011 Census [40]. The climate is tropical and transmission may occur throughout the year provided the relative humidity levels support the vector survival. Ujjain district has low transmission of malaria with annual parasite index (API) $<0.1$ in 2010 [41]. Peak malaria transmission occurs during the warm and humid months of July to September. Data collection was, therefore, done from June to October in 2009 and 2010.

\section{Recruitment of patients and sample collection}

Samples and data were collected by the nine major pathology laboratories located in Ujjain city, Madhya Pradesh, India. Individuals or groups of pathologists with a postgraduate degree in pathology reported the results from participating laboratories. All laboratories used microscopical examination of peripheral blood smear for the diagnosis of $P$. falciparum malaria. The only inclusion criterion was microscopically verified malaria. For 
all patients that were smear positive for malaria, a drop of blood was put onto filter papers (Whatman ${ }^{\mathrm{TM}} 3 \mathrm{MM}$ ). The filter papers were labelled with the patient's age and sex, dried and then placed inside individual sealed plastic bags.

\section{Sample storage, DNA extraction}

Filter papers were stored at room temperature. DNA was extracted using QIAamp Blood Mini Kit (QIAgen Biosciences, Germantown, MD, USA) according to the manufacturer's instructions. Extracted DNA was stored at $-20^{\circ} \mathrm{C}$ until use.

\section{Molecular analyses}

Pfcrt 72-76, pfmdr1 1034-1246, pfdhfr 16-185, pfdhps 436-632 and pfnhe1 ms4760 haplotypes were identified by PCR amplification followed by sequencing using previously described PCR protocols [23,37,42-44]. The Sequencher $^{\mathrm{Tm}}$ software version 4.6 (Gene Codes Corporation, Ann Arbor, MI, USA) was used for sequencing analysis. The P. falciparum 3D7 clone sequences obtained from NCBI database was used as references for pfcrt (Accession no NC_004328), pfindr1 (Accession no XM_001351751.1), pfdhfr (Accession no XM_001351443.1) and pfdhps (Accession no XM_001349382.1). Pfnhe1 ms4760 sequences were compared with previously described isolates and clones.

In addition, previously described multiplex PCRRFLP (restriction fragment length polymorphism) methods were used to identify pfcrt K76T and pfmdr1 N86Y SNPs $[23,45,46]$.

PCR and restriction products were resolved on $2 \%$ agarose gels (Amresco, Solon, OH, USA). All gels were stained with a nucleic acid gel stain $\left(\right.$ GelRed ${ }^{\mathrm{TM}}$, Biotium Inc, Hayward, CA, USA) and visualized under UV transillumination (GelDoc ${ }^{\oplus}$, Biorad, Hercules, CA, USA). PCR products were purified and sequenced commercially (Macrogen Inc, Seoul, Korea).

Pfmdr1 copy numbers were determined using real time PCR (ABI Prism 7000 Sequence Detection System). Real time PCR reactions were run in triplicate for each sample as previously described [47]. P. falciparum strains 3D7, D10 and K1 with single copies of the pfmdr1 gene were used as calibrators and FCB and Dd2 strains with multiple copies of the gene were used as controls. The sample copy numbers were calculated using a comparative threshold method $(\Delta \Delta \mathrm{CT})$. Assays were repeated if the following results were obtained: copy number $1.3-1.6$ and $2.3-2.6$ or CT value $>35$ or standard deviation value $>0.5$. Samples with repeated CT values $>35$ were considered to have failed.

\section{Statistical analyses}

The exact incidence of $P$. falciparum malaria was not known and we therefore decided to collect as many samples as possible over a two year period. SNP frequencies were calculated by dividing the number of SNPs by the number of patients in whom a certain the allele could be identified. Allele frequencies in 2009 and 2010 were compared using Chi-squared tests.

\section{Ethics}

Patients with uncomplicated malaria were enrolled and samples collected after informed oral consent of the patient or in the case of minors informed proxy-consent of their parent or guardian. The study was approved by the Institutional Ethics Committee of R D Gardi Medical College in Ujjain, Madhya Pradesh, India (61/2009) and the Regional Ethics Committee in Stockholm, Sweden (2011/832-32/2).

\section{Results}

During the peak malaria seasons 2009 and 2010, 44 and 43 (total 87) patients with microscopically verified P. falciparum mono-infection were identified and included. The median age was 30 years (inter quartile range $15-30$ years). Forty-four patients were male and 34 female, for the remaining nine individuals sex was not recorded. PCR was successful for at least one allele in all 87 samples. There were no significant differences in SNP frequencies between 2009 and 2010.

\section{Pfdhfr and pfdhps}

The number of resistance-associated SNPs and haplotypes are shown in Tables 1 and 2. The resistanceassociated pfdhfr $108 \mathrm{~N}$ and 59R alleles were found in 75/78 (96\%) 70/78 (90\%) samples, respectively. No sample had resistance-associated SNPs at codons 16, 50, 51 or 164. Pfdhfr $108 \mathrm{~N}$ and 59R alleles were found together in $70 / 78(90 \%)$ of samples.

The resistance-associated pfdhps 437G allele was found in 7/77 (9\%) samples. No resistance-associated alleles were detected at codons 540,581 or 613 . All samples (76/76) carried the resistance-associated 436F allele.

Combined pfdhfr and pfdhps haplotypes were identified in 76 samples. Double mutant pfdhfr $59 \mathrm{R}+108 \mathrm{~N}$ were found in $62 / 76$ (82\%) samples and double mutant pfdhfr $108 \mathrm{~N}$ and pfdhps $437 \mathrm{G}$ was found in $1 / 76(1 \%)$

Table 1 The number and frequency of resistance-associated pfdhfr and pfdhps alleles in Plasmodium falciparum samples collected Ujjain, Madhya Pradesh, India in 2009 and 2010

\begin{tabular}{llllll}
\hline Pfdhfr & A16V & N51I & C59R & S108N & I164L \\
\hline Sensitive & $69 / 69$ & $78 / 78$ & $8 / 78(10 \%)$ & $3 / 78(4 \%)$ & 78/78 \\
Resistant & $0 / 69$ & $0 / 78$ & $70 / 78(90 \%)$ & $75 / 78(96 \%)$ & 0/78 \\
\hline Pfdhps & S436F & A437G & K540E & A581G & A613T \\
\hline Sensitive & $0 / 76$ & $70 / 77(91 \%)$ & $77 / 77$ & $77 / 77$ & 77/77 \\
Resistant & $76 / 76$ & $7 / 77(9 \%)$ & $0 / 77$ & $0 / 77$ & $0 / 77$ \\
\hline
\end{tabular}


Table 2 The number and frequency of pfdhfr and pfdhps resistance-associated haplotypes in Plasmodium falciparum samples collected in Ujjain, Madhya Pradesh, India in 2009 and 2010

\begin{tabular}{|c|c|c|c|c|c|c|c|c|c|c|}
\hline \multirow[t]{2}{*}{ No of each haplotype } & \multirow[t]{2}{*}{ No SNPs* } & \multicolumn{4}{|c|}{ Pfdhfr } & \multicolumn{5}{|c|}{ Pfdhps } \\
\hline & & 51 & 59 & 108 & 164 & 436 & 437 & 540 & 581 & 613 \\
\hline $3(4 \%)$ & 1 & N & $C$ & $S$ & । & $F$ & A & K & A & $A$ \\
\hline $4(5 \%)$ & 2 & $\mathrm{~N}$ & $C$ & $N$ & । & $F$ & A & K & A & A \\
\hline $1(1 \%)$ & 3 & $\mathrm{~N}$ & $C$ & $N$ & । & $F$ & $G$ & K & A & A \\
\hline $62(82 \%)$ & 3 & N & $R$ & $N$ & । & $F$ & A & K & $A$ & $A$ \\
\hline $6(8 \%)$ & 4 & N & $R$ & $N$ & 1 & $F$ & $G$ & K & A & A \\
\hline 2 & 2 & $\mathrm{~N}$ & $R$ & $N$ & 1 & & & & & \\
\hline 1 & 1 & & & & & $F$ & $A$ & K & $A$ & $A$ \\
\hline
\end{tabular}

Resistance associated alleles are written in bold and are italics.

* Number of resistance-associated SNPs in each haplotype.

Haplotype proportions were calculated from the total number (76) of samples in which both pfdhfr and pfdhps haplotypes were identified.

samples. Triple mutant pfdhfr 59R $+108 \mathrm{~N}$ and pfdhps $437 \mathrm{G}$ were found in 6/76 (8\%) samples. All these haplotypes also had the $436 \mathrm{~F}$ allele potentially adding one resistance-associated SNP to each haplotype.

\section{Pfcrt}

Pfcrt 76T was found in 82/87 (94\%) and pfcrt K76 was found in 5/87 (6\%) of samples. The pfcrt 72-76 haplotypes found were: 80/84 (95\%) SVMNT, 3/84 (4\%) CVMNK and $1 / 84$ (1\%) CVMNT. Sequencing failed altogether in three samples and identified only the pfcrt 72-75 haplotype in 13 samples. In these 13 samples, the 76 allele was detected using PCR-RFLP (Table 3).

\section{Pfmdr1}

Pfmdr1 N86 and 86Y were identified in 70/83 (84\%) and 13/83 (16\%) samples, respectively. Pfmdr1 86Y only occurred together with pfcrt 76 T. Pfmdr1 S1034 + N1042 were identified together in all 75 successfully sequenced samples. Pfmdr1 D1246 and 1246Y were identified in 70/72 (97\%) and 2/72 (3\%) samples, respectively. No sample had the pfmdr1 $1226 \mathrm{Y}$ allele associated with reduced sensitivity to artemisinin, lumefantrine and mefloquine [48].

One pfmdr1 gene copy was found in 74/75 (99\%) successfully amplified samples. After repeating PCRs three times, one sample had two pfmdr1 copies and six samples had an indeterminate number of copies with $\Delta \Delta \mathrm{Ct}$ (cycle threshold) values consistently between 1.3 and 1.6. PCRs failed in six samples primarily due to $\mathrm{CT}$ values above the 35-cycle cut-off. Further details are shown in Table 3.

\section{Pfnhe1}

The numbers of DNNND and DDNHNDNHNND repeats in pfnhe1 ms4760 were identified in 74/87 (85\%) samples (Table 3). Five previously described pfnhe1 ms4760 profiles were detected at the following frequencies: ms4760-1 $(\mathrm{n}=4), \operatorname{ms} 4760-2(\mathrm{n}=14), \operatorname{ms} 4760-5(\mathrm{n}=7), \operatorname{ms} 4760-6$ $(n=46)$, ms4760-7 $(n=3)$. More than one DNNND repeat was found in $60 / 74$ (81\%) samples. The numbers of DDNHNDNHNND repeats were one in 56/74 (76\%) and two in $18 / 74$ (24\%) of samples. The numbers of repeats were not associated with any SNP or haplotypes in pfcrt, pfindr1, pfdhfr or pfdhps.

\section{Discussion}

This is the first characterization of key anti-malarial drug resistance associated genetic polymorphisms among $P$. falciparum field isolates in Ujjain, Madhya Pradesh, central India. Importantly, this study was conducted prior to implementation of artemisinin-based combination therapy (ACT) in Ujjain and thus provides baseline data on the prevalence of resistance-associated polymorphisms prior to the introduction of ASP. From these data the prevalence of in vivo CQ and SP resistance in the study area can be inferred. The data also provide baseline information for future temporal surveillance of resistanceassociated genetic polymorphisms in the study area as well as for comparisons with neighbouring areas.

Despite this study being conducted prior to the introduction of ASP, the SP resistance-associated 436F allele was found in all samples. This is an allele that has previously been described in several Indian states and that has been found to modulate SP susceptibility [21]. Typically, SP resistance arises through sequential selection of SNPs, starting with pfdhfr $108 \mathrm{~N}$ and 59R followed by SNPs in pfdhps [15]. It is thus most likely that $436 \mathrm{~F}$ is a wild type allele in Ujjain. Nevertheless, it may well result in a degree of reduced susceptibility to SP [12].

The majority $(82 \%)$ of samples in this study carried the SP resistance-associated double pfdhfr $59 \mathrm{R}$ and $108 \mathrm{~N}$ together with pfdhps 436F. This suggests a moderate degree of reduced susceptibility to SP and a low risk of treatment failure at the time of the study. Furthermore, only one sample had two pfmdrl gene copies that have 
Table 3 The number and frequency of pfcrt, pfmdr1 and pfnhe ms 4760 alleles in Plasmodium falciparum field samples collected in Ujjain, Madhya Pradesh, India in 2009 and 2010

\begin{tabular}{llll}
\hline Gene & Polymorphism/no of repeats & Number/total* & Proportion (\%) \\
\hline Pfcrt 76 & K & $5 / 87$ & 6 \\
& $T$ & $82 / 87$ & 94 \\
Pfmdr1 & N & & 84 \\
$\mathbf{8 6}$ & Y & $70 / 83$ & 16 \\
$\mathbf{8 6}$ & SN & $13 / 83$ & 100 \\
$\mathbf{1 0 3 4 + 1 0 4 2}$ & $\mathrm{N}$ & $75 / 75$ & 97 \\
$\mathbf{1 2 4 6}$ & $Y$ & $70 / 72$ & 3 \\
$\mathbf{1 2 4 6}$ & 1 & $2 / 72$ & 99 \\
Gene copy numbert & 2 & $74 / 75$ & 1 \\
& 1 & $1 / 75$ & 19 \\
Pfnhe ms4760 DNNND repeats & 2 & $14 / 74$ & 68 \\
& 3 & $50 / 74$ & 4 \\
Pfnhe ms4760 DDNHNDNHNND & 4 & $3 / 74$ & 9 \\
Repeats & 1 & $7 / 74$ & 76 \\
\hline
\end{tabular}

* Total number of polymorphisms successfully identified at each locus.

†Pfmdr1 gene copy number was between one and two $(\Delta \Delta \mathrm{Ct}$ 1.3-1.6) in six samples and PCRs failed in six samples.

All pfmdr1 86Y occurred together with pfcrt $76 \mathrm{~T}$. Pfmdr1 1246Y alleles occurred together with pfcrt $76 \mathrm{~T}$ and pfmdr1 N86.

been linked to reduced artemisinin susceptibility. Based on these findings, it is likely that ASP is highly efficacious for treatment of uncomplicated P. falciparum malaria in Ujjain. However, four samples had pfdhfr 59R + $108 \mathrm{~N}$ and pfdhps $436 \mathrm{~F}+437 \mathrm{G}$ indicating that these parasite subpopulations only need to acquire one more SNP in pfdhfr to become similar to P. falciparum that was associated with treatment failure in nearby West Bengal (pfdhfr 51I $+59 \mathrm{R}+108 \mathrm{~N}$ and pfdhps $437 \mathrm{G}$ or $436 \mathrm{~A}+540 \mathrm{E})$ [8]. This is particularly concerning considering that this report is based on data collected before ASP was introduced in Ujjain.

Of even greater concern, previous experience suggests that SP resistance can and will spread rapidly despite the concurrent use of artesunate. Specifically, the prevalence of the quintuple DHFR + DHPS haplotype increased from 11 to $75 \%$ after only four years of using ASP in Mozambique [49]. Furthermore, CQ resistance swept across India and SP resistance spread through Southeast Asia in the past [50]. The existence of highly SP-resistant P. falciparum on the Andaman and Nicobar islands as well as in northeastern India is, therefore, worrisome [18-21]. Spread of SP resistance will in turn expose artesunate to a high selective pressure, which may spur development and spread of new foci of decreased susceptibility to artemisinin. This highlights the need for continual monitoring of drug resistance in Ujjain as well as the rest of India.

The $95 \%$ prevalence of pfcrt $76 \mathrm{~T}$ in Ujjain is similar to data from many other parts of India as well as neighbouring countries such as Pakistan [51,52]. The high prevalence suggests that treatment failure rates following intake of a total dose of $25 \mathrm{mg} / \mathrm{kg}$ of CQ are likely to be similar to the $~ 70 \%$ treatment failure rate reported from Goa in 2011, when the $76 \mathrm{~T}$ prevalence was $100 \%$ [53]. In view of the high prevalence of pfcrt 76T, replacing CQ was undoubtedly the correct decision also for Ujjain. Sequencing of the pfcrt 72-76 haplotype identified the typical CQ "wild type" CVMNK haplotype associated with CQ sensitivity in the three patients that had K76. In patients harbouring the 76T allele, the principle haplotype found was SVMNT. This is the most common haplotype in India as well as Pakistan, Iran and probably originates from Papua New Guinea [17,51,52,54]. In addition, haplotype CVMNT that has also been described previously in India, was found [53]. Thus the pfort SNPs found in Ujjain are the same as in most of India in line with previous studies showing how CQ resistance spread throughout the country.

Given the proximity and similar genetic background of CQ-resistant $P$. falciparum in India and Pakistan it is likely that the genetic mechanism causing resistance is similar. It is therefore noteworthy that changing the CQ dosing schedule to $40 \mathrm{mg} / \mathrm{kg}$ as divided doses over five days compared to the standard $25 \mathrm{mg} / \mathrm{kg}$ over three days approximately doubled the efficacy of CQ (49 vs 26\%) in Pakistan [52]. Although 49\% efficacy is unacceptably low, this does suggest that CQ resistance is dose dependent in P. falciparum with pfcrt 72-76 SVMNT. Similarly, treatment with $50 \mathrm{mg} / \mathrm{kg}$ compared to $25 \mathrm{mg} / \mathrm{kg}$ over three 
days approximately doubled the efficacy (78 vs 38\%) of CQ in P. falciparum with $p f c r t 72-76$ CVIET in West Africa [55]. It may therefore be worth considering whether increasing the dose and treatment duration of CQ can improve the efficacy of CQ in India. This is potentially interesting as considerably higher $\mathrm{CQ}$ doses given for longer periods can be well tolerated [56,57]. However, it is not known to what degree efficacy could potentially be improved with a higher dose regimen.

The finding of only one pfmdr1 gene copy number in all but one sample indicates that P. falciparum in Ujjain do not presently have reduced susceptibility to artemisnin derivatives, lumefantrine, piperaquine or mefloquine [31]. However, in transfection experiments pfmdrl alleles S1034, N1042 and D1246 have been linked to reduced mefloquine and artemisinin sensitivity [29]. Thus the P. falciparum population in Ujjain have $p f m d r 1$ alleles that possibly are linked to reduced artemisinin sensitivity. The lack of $p f m d r 1$ amplifications and high prevalence of pfcrt $76 \mathrm{~T}$ suggests that artemether-lumefantrine would be efficacious in Ujjain.

The pfnhe1 ms4760-6 haplotype that has two DNNND repeats and one DDNHNDNHNND repeat was predominant in Ujjain. In other studies in Asia the ms4760-7 haplotype that has three DNNND repeats and one NHNDNHNNDDD repeat has been the most prevalent $[38,39,58]$. Both these profiles have been found to have similarly reduced quinine sensitivity, suggesting that $P$. falciparum with a degree of reduced quinine sensitivity is prevalent in Ujjain [39]. However, the pfmdr1 86, 1034, 1042 and 1246 NSND haplotype that was highly prevalent in Ujjain has been associated with quinine sensitivity $[29,59]$. Also, none of the above is a marker of quinine treatment failure and the correlation with quinine susceptibility is not fully elucidated. Thus, available data are difficult to interpret but provide a baseline for future monitoring.

The principle limitation of this study is the relatively small sample size. However, there was no obvious bias in sample collection and the data are therefore probably representative of the study area. There is also a lack local knowledge about the correlation between the various molecular markers studied and reduced drug susceptibility. However, the principle CQ and SP resistance markers studied have been verified in clinical studies in India and found to be valid.

\section{Conclusions}

This is the first report on anti-malarial resistance-associated SNPs among $P$. falciparum field isolates in Ujjain, Madhya Pradesh, central India, collected prior to the introduction of ASP. The results indicate that the efficacy of standard dose CQ was likely to be poor whereas ASP was likely to be efficacious supporting the shift from CQ to ASP as first line anti-malarial drug for uncomplicated $P$. falciparum malaria. However, P. falciparum with reduced susceptibility to SP is highly prevalent, highlighting the need for continuous surveillance of ASP efficacy.

\section{Abbreviations}

ASP: Artesunate + sulphadoxine-pyrimethamine; CQ: Chloroquine; SNP: Single nucleotide polymorphisms; pfdhfr: P. falciparum dihydrofolate reductase gene; pfdhps: $P$. falciparum dihydropteroate synthase gene; pfcrt: $P$. falciparum chloroquine resistance transporter gene; $p f m d r 1: P$. falciparum multidrug resistance gene 1; pfnhe1: $P$. falciparum sodium/hydrogen exchanger gene and $\Delta \Delta \mathrm{Ct}$, difference in cycle threshold.

\section{Competing interests}

The authors have declared that they have no competing interests.

\section{Authors' contributions}

$A P, A M$ and $J U$ conceived the study. AP organized data collection. AP, AM, SG, JM, AS, VD, and JU designed the methodology. AP, SG, JM, AS, and VD collected the field samples. AP, AM and JU conducted the molecular analyses. AP, JU and AM drafted the manuscript. SBG, JM, AS, and VD provided valuable insights during the revision and editing of the manuscript. All authors read and approved the final manuscript.

\section{Acknowledgements}

The authors acknowledge the help of Dr G K Nagar, Dr Girish Jarare, Dr Kishore Jhamnani and Dr Manju Purohit in data collection. We thank all the patients for giving us consent to collect the blood samples. AM received a SASNET planning grant (RPG09:12) for the project.

\section{Author details}

'Department of Pediatrics, R D Gardi Medical College, Surasa, Ujjain 456010 India. ${ }^{2}$ Department of Women and Children's Health, International Maternal and Child Health Unit, Uppsala University, Uppsala SE 751 85, Sweden. ${ }^{3}$ Department of Public Health Sciences (Global Health/IHCAR), Karolinska Institutet, Tomtebodavägen 18A, Stockholm SE 171 77, Sweden. ${ }^{4}$ Malaria Research, Department of Medicine Solna, Karolinska Institutet, Stockholm, Sweden. ${ }^{5}$ Department of Medicine, R D Gardi Medical College, Surasa, Ujjain 456010, India. ${ }^{6}$ Public Health \& Environment in R D Gardi Medical College, Ujjain, India. ${ }^{7}$ Centre for Clinical Research, Sörmland County Council, Sörmland, Sweden.

Received: 23 March 2014 Accepted: 7 May 2014 Published: 15 May 2014

\section{References}

1. Sharma VP: Current scenario of malaria in India. Parassitologia 1999, 41:349-353.

2. Kumar A, Valecha N, Jain T, Dash AP: Burden of malaria in India: retrospective and prospective view. Am J Trop Med Hyg 2007, 77:69-78.

3. WHO: World malaria report. Geneva: World Health Organization; 2012. http:// www.who.int/malaria/publications/world_malaria_report_2012/en/index.html.

4. Shah NK, Dhillon GP, Dash AP, Arora U, Meshnick SR, Valecha N: Antimalarial drug resistance of Plasmodium falciparum in India: changes over time and space. Lancet Infect Dis 2011, 11:57-64.

5. Dondorp AM, Nosten F, Yi P, Das D, Phyo AP, Tarning J, Lwin KM, Ariey F Hanpithakpong W, Lee SJ, Ringwald P, Silamut K, Imwong M, Chotivanich K, Lim P, Herdman T, An SS, Yeung S, Singhasivanon P, Day NP, Lindegardh N, Socheat D, White NJ: Artemisinin resistance in Plasmodium falciparum malaria. N Engl J Med 2009, 361:455-467.

6. Phyo AP, Nkhoma S, Stepniewska K, Ashley EA, Nair S, McGready R, ler Moo C, Al- Saai S, Dondorp AM, Lwin KM, Singhasivanon P, Day NP, White NJ, Anderson TJ, Nosten F: Emergence of artemisinin-resistant malaria on the western border of Thailand: a longitudinal study. Lancet 2012, 379:1960-1966.

7. Mita T, Tanabe K, Kita K: Spread and evolution of Plasmodium falciparum drug resistance. Parasitol Int 2009, 58:201-209.

8. Saha P, Guha SK, Das S, Mullick S, Ganguly S, Biswas A, Bera DK, Chattopadhyay G, Das M, Kundu PK, Ray K, Maji AK: Comparative efficacies of artemisinin combination therapies in Plasmodium falciparum malaria 
and polymorphism of pfATPase6, pfcrt, pfdhfr, and pfdhps genes in tea gardens of Jalpaiguri district, India. Antimicrob Agents Chemother 2012, 56:2511-2517

9. Cowman AF, Morry MJ, Biggs BA, Cross GA, Foote SJ: Amino acid changes linked to pyrimethamine resistance in the dihydrofolate reductase-thymidylate synthase gene of Plasmodium falciparum. Proc Natl Acad Sci U S A 1988, 85:9109-9113.

10. Peterson DS, Walliker D, Wellems TE: Evidence that a point mutation in dihydrofolate reductase-thymidylate synthase confers resistance to pyrimethamine in falciparum malaria. Proc Natl Acad Sci U S A 1988, 85:9114-9118

11. Peterson DS, Milhous WK, Wellems TE: Molecular basis of differential resistance to cycloguanil and pyrimethamine in Plasmodium falciparum malaria. Proc Natl Acad Sci U S A 1990, 87:3018-3022.

12. Plowe CV, Kublin JG, Doumbo OK: P. falciparum dihydrofolate reductase and dihydropteroate synthase mutations: epidemiology and role in clinical resistance to antifolates. Drug Resist Updat 1998, 1:389-396.

13. Foote SJ, Galatis D, Cowman AF: Amino acids in the dihydrofolate reductase-thymidylate synthase gene of Plasmodium falciparum involved in cycloguanil resistance differ from those involved in pyrimethamine resistance. Proc Natl Acad Sci U S A 1990, 87:3014-3017.

14. Triglia T, Menting JG, Wilson C, Cowman AF: Mutations in dihydropteroate synthase are responsible for sulfone and sulfonamide resistance in Plasmodium falciparum. Proc Natl Acad Sci U S A 1997, 94:13944-13949.

15. Mita T, Ohashi J, Venkatesan M, Marma AS, Nakamura M, Plowe CV, Tanabe K. Ordered accumulation of mutations conferring resistance to sulfadoxine-pyrimethamine in the Plasmodium falciparum parasite. J Infect Dis 2013, 209:130-139.

16. Kublin JG, Dzinjalamala FK, Kamwendo DD, Malkin EM, Cortese JF, Martino LM, Mukadam RA, Rogerson SJ, Lescano AG, Molyneux ME, Winstanley PA Chimpeni P, Taylor TE, Plowe CV: Molecular markers for failure of sulfadoxine-pyrimethamine and chlorproguanil-dapsone treatment of Plasmodium falciparum malaria. J Infect Dis 2002, 185:380-388.

17. Awasthi G, Prasad GB, Das A: Population genetic analyses of Plasmodium falciparum chloroquine receptor transporter gene haplotypes reveal the evolutionary history of chloroquine-resistant malaria in India. Int $J$ Parasitol 2011, 41:705-709.

18. Lumb V, Das MK, Singh N, Dev V, Wajihullah, Sharma YD: Characteristics of genetic hitchhiking around dihydrofolate reductase gene associated with pyrimethamine resistance in Plasmodium falciparum isolates from India. Antimicrob Agents Chemother 2009, 53:5173-5180.

19. Lumb V, Das MK, Mittra P, Ahmed A, Kumar M, Kaur P, Dash AP, Singh SS, Sharma YD: Emergence of an unusual sulfadoxine-pyrimethamine resistance pattern and a novel $\mathrm{K} 540 \mathrm{~N}$ mutation in dihydropteroate synthetase in Plasmodium falciparum isolates obtained from Car Nicobar Island, India, after the 2004 Tsunami. J Infect Dis 2009, 199:1064-1073.

20. Ahmed A, Lumb V, Das MK, Dev V, Wajihullah, Sharma YD: Prevalence of mutations associated with higher levels of sulfadoxine-pyrimethamine resistance in Plasmodium falciparum isolates from Car Nicobar Island and Assam, India. Antimicrob Agents Chemother 2006, 50:3934-3938.

21. Ahmed A, Bararia D, Vinayak S, Yameen M, Biswas S, Dev V, Kumar A, Ansari MA, Sharma YD: Plasmodium falciparum isolates in India exhibit a progressive increase in mutations associated with sulfadoxinepyrimethamine resistance. Antimicrob Agents Chemother 2004, 48:879-889.

22. Wootton JC, Feng X, Ferdig MT, Cooper RA, Mu J, Baruch DI, Magill AJ, Su XZ: Genetic diversity and chloroquine selective sweeps in Plasmodium falciparum. Nature 2002, 418:320-323.

23. Djimde A, Doumbo OK, Cortese JF, Kayentao K, Doumbo S, Diourte Y, Dicko A, Su XZ, Nomura T, Fidock DA, Wellems TE, Plowe CV, Coulibaly D: A molecular marker for chloroquine-resistant falciparum malaria. N Engl J Med 2001, 344:257-263.

24. Fidock DA, Nomura T, Talley AK, Cooper RA, Dzekunov SM, Ferdig MT, Ursos LM, Sidhu AB, Naude B, Deitsch KW, SU XZ, Wootton JC, Roepe PD, Wellems TE: Mutations in the $P$. falciparum digestive vacuole transmembrane protein PfCRT and evidence for their role in chloroquine resistance. Mol Cell 2000, 6:861-871.

25. Mixson-Hayden T, Jain V, McCollum AM, Poe A, Nagpal AC, Dash AP, Stiles JK, Udhayakumar V, Singh N: Evidence of selective sweeps in genes conferring resistance to chloroquine and pyrimethamine in Plasmodium falciparum isolates in India. Antimicrob Agents Chemother 2010, 54:997-1006.
26. Das Sutar SK, Dhangadamajhi G, Kar SK, Ranjit M: Molecular monitoring of antimalarial drug resistance among Plasmodium falciparum field isolates from Odisha. India Acta Trop 2013, 126:84-87.

27. Vinayak S, Biswas S, Dev V, Kumar A, Ansari MA, Sharma YD: Prevalence of the K76T mutation in the pfcrt gene of Plasmodium falciparum among chloroquine responders in India. Acta Trop 2003, 87:287-293.

28. Chauhan K, Pande V, Das A: Analyses of genetic variations at microsatellite loci present in-and-around the Pfcrt gene in Indian Plasmodium falciparum. Infect Genet Evol 2013, 20C:476-487.

29. Reed MB, Saliba KJ, Caruana SR, Kirk K, Cowman AF: Pgh1 modulates sensitivity and resistance to multiple antimalarials in Plasmodium falciparum. Nature 2000, 403:906-909.

30. Mu J, Ferdig MT, Feng X, Joy DA, Duan J, Furuya T, Subramanian G, Aravind L, Cooper RA, Wootton JC, Xiong M, Su XZ: Multiple transporters associated with malaria parasite responses to chloroquine and quinine. Mol Microbiol 2003, 49:977-989.

31. Cui L, Wang Z, Miao J, Miao M, Chandra R, Jiang H, Su XZ: Mechanisms of in vitro resistance to dihydroartemisinin in Plasmodium falciparum. Mol Microbiol 2012, 86:111-128.

32. Price RN, Cassar C, Brockman A, Duraisingh $M$, van Vugt $M$, White NJ, Nosten F, Krishna S: The pfmdr1 gene is associated with a multidrug-resistant phenotype in Plasmodium falciparum from the western border of Thailand. Antimicrob Agents Chemother 1999, 43:2943-2949.

33. Sidhu AB, Uhlemann AC, Valderramos SG, Valderramos JC, Krishna S, Fidock DA: Decreasing pfmdr1 copy number in Plasmodium falciparum malaria heightens susceptibility to mefloquine, lumefantrine, halofantrine, quinine, and artemisinin. J Infect Dis 2006, 194:528-535.

34. Veiga MI, Ferreira PE, Malmberg M, Jornhagen L, Bjorkman A, Nosten F, Gil JP. Pfmdr1 amplification is related to increased Plasmodium falciparum in vitro sensitivity to the bisquinoline piperaquine. Antimicrob Agents Chemother 2012, 56:3615-3619.

35. Sisowath C, Petersen I, Veiga MI, Martensson A, Premji Z, Bjorkman A, Fidock DA, Gil JP: In vivo selection of Plasmodium falciparum parasites carrying the chloroquine-susceptible pfcrt K76 allele after treatment with artemether-lumefantrine in Africa. J Infect Dis 2009, 199:750-757.

36. Sisowath C, Stromberg J, Martensson A, Msellem M, Obondo C, Bjorkman A, Gil JP: In vivo selection of Plasmodium falciparum pfmdr1 $86 \mathrm{~N}$ coding alleles by artemether-lumefantrine (Coartem). J Infect Dis 2005, 191:1014-1017.

37. Malmberg M, Ferreira PE, Tarning J, Ursing J, Ngasala B, Bjorkman A, Martensson A, Gil JP: Plasmodium falciparum drug resistance phenotype as assessed by patient antimalarial drug levels and its association with pfmdr1 polymorphisms. J Infect Dis 2013, 207:842-847.

38. Ferdig MT, Cooper RA, Mu J, Deng B, Joy DA, Su XZ, Wellems TE: Dissecting the loci of low-level quinine resistance in malaria parasites. Mol Microbiol 2004, 52:985-997.

39. Sinou V, Quang le H, Pelleau S, Huong VN, Huong NT, Tai le M, Bertaux L, Desbordes M, Latour C, Long LQ, Thanh NX, Parzy D: Polymorphism of Plasmodium falciparum $\mathrm{Na}(+) / \mathrm{H}(+)$ exchanger is indicative of a low in vitro quinine susceptibility in isolates from Viet Nam. Malar J 2011, 10:164.

40. Ujjain District: Census 2011 data. [http://www.census2011.co.in/census/ district/302-ujjain.html]

41. National Vector Borne Disease Control Programme: Annual Parasite Index, Madhya Pradesh. [http://nvbdcp.gov.in/images/MadhyaPrd.jpg]

42. Vinayak S, Alam MT, Mixson-Hayden T, McCollum AM, Sem R, Shah NK, Lim P, Muth S, Rogers WO, Fandeur T, Barnwell JW, Escalante AA, Wongsrichanalai C, Ariey F, Meshnick SR, Udhayakumar V: Origin and evolution of sulfadoxine resistant Plasmodium falciparum. PLoS Pathog 2010, 6:e1000830.

43. Alam MT, de Souza DK, Vinayak S, Griffing SM, Poe AC, Duah NO, Ghansah A, Asamoa K, Slutsker L, Wilson MD, Barnwell JW, Udhayakumar V, Koram KA: Selective sweeps and genetic lineages of Plasmodium falciparum drug -resistant alleles in Ghana. J Infect Dis 2011, 203:220-227.

44. Kone A, Mu J, Maiga H, Beavogui AH, Yattara O, Sagara I, Tekete MM, Traore OB, Dara A, Dama S, Diallo N, Kodio A, Traore A, Bjorkman A, Gil JP, Duombo OK, Wellems TE, Djimde AA: Quinine treatment selects the pfnhe-1 ms4760-1 polymorphism in Malian patients with Falciparum malaria. J Infect Dis 2013, 207:520-527.

45. Veiga MI, Ferreira PE, Bjorkman A, Gil JP: Multiplex PCR-RFLP methods for pfcrt, pfmdr1 and pfdhfr mutations in Plasmodium falciparum. Mol Cell Probes 2006, 20:100-104

46. Holmgren G, Hamrin J, Svard J, Martensson A, Gil JP, Bjorkman A: Selection of pfmdr1 mutations after amodiaquine monotherapy and amodiaquine 
plus artemisinin combination therapy in East Africa. Infect Genet Evol 2007, 7:562-569.

47. Price RN, Uhlemann AC, Brockman A, McGready R, Ashley E, Phaipun L, Patel R, Laing K, Looareesuwan S, White NJ, Nosten F, Krishna S: Mefloquine resistance in Plasmodium falciparum and increased pfmdr1 gene copy number. Lancet 2004, 364:438-447.

48. Veiga MI, Ferreira PE, Jornhagen L, Malmberg M, Kone A, Schmidt BA, Petzold M, Bjorkman A, Nosten F, Gil JP: Novel polymorphisms in Plasmodium falciparum $A B C$ transporter genes are associated with major ACT antimalarial drug resistance. PLoS One 2011, 6:e20212.

49. Raman J, Little F, Roper C, Kleinschmidt I, Cassam Y, Maharaj R, Barnes Kl: Five years of large-scale dhfr and dhps mutation surveillance following the phased implementation of artesunate plus sulfadoxine-pyrimethamine in Maputo Province, Southern Mozambique. Am J Trop Med Hyg 2010, 82:788-794.

50. Nair S, Williams JT, Brockman A, Paiphun L, Mayxay M, Newton PN Guthmann JP, Smithuis FM, Hien TT, White NJ, Nosten F, Anderson TJ: A selective sweep driven by pyrimethamine treatment in southeast asian malaria parasites. Mol Biol Evol 2003, 20:1526-1536.

51. Ghanchi NK, Ursing J, Beg MA, Veiga MI, Jafri S, Martensson A: Prevalence of resistance associated polymorphisms in Plasmodium falciparum field isolates from southern Pakistan. Malar J 2011, 10:18.

52. Howard N, Durrani N, Sanda S, Beshir K, Hallett R, Rowland M: Clinical trial of extended-dose chloroquine for treatment of resistant falciparum malaria among Afghan refugees in Pakistan. Malar J 2011, 10:171.

53. Valecha N, Joshi H, Mallick PK, Sharma SK, Kumar A, Tyagi PK, Shahi B, Das MK Nagpal BN, Dash AP: Low efficacy of chloroquine: time to switchover to artemisinin-based combination therapy for falciparum malaria in India. Acta Trop 2009, 111:21-28.

54. Ursing J, Zakeri S, Gil JP, Bjorkman A: Quinoline resistance associated polymorphisms in the pfcrt, pfmdr1 and pfmrp genes of Plasmodium falciparum in Iran. Acta Trop 2006, 97:352-356.

55. Ursing J, Kofoed PE, Rodrigues A, Rombo L, Gil JP: Plasmodium falciparum genotypes associated with chloroquine and amodiaquine resistance in Guinea-Bissau. Am J Trop Med Hyg 2007, 76:844-848.

56. Canete R, Rivas DE, Escobedo AA, Gonzalez ME, Almirall P, Brito K: A randomized, controlled, open-label trial evaluating the efficacy and safety of chloroquine in the treatment of giardiasis in children. West Indian Med J 2010, 59:607-611.

57. Ursing J, Kofoed PE, Rodrigues A, Bergqvist Y, Rombo L: Chloroquine is grossly overdosed and overused but well tolerated in Guinea-bissau. Antimicrob Agents Chemother 2009, 53:180-185.

58. Meng H, Zhang R, Yang H, Fan Q, Su X, Miao J, Cui L, Yang Z: In vitro sensitivity of Plasmodium falciparum clinical isolates from the China-Myanmar border area to quinine and association with polymorphism in the $\mathrm{Na}+/ \mathrm{H}+$ exchanger. Antimicrob Agents Chemother 2010, 54:4306-4313.

59. Poyomtip T, Suwandittakul N, Sitthichot N, Khositnithikul R, Tan-ariya P, Mungthin M: Polymorphisms of the pfmdr1 but not the pfnhe-1 gene is associated with in vitro quinine sensitivity in Thai isolates of Plasmodium falciparum. Malar J 2012, 11:7.

doi:10.1186/1475-2875-13-182

Cite this article as: Pathak et al:: Characterization of drug resistance associated genetic polymorphisms among Plasmodium falciparum field isolates in Ujjain, Madhya Pradesh, India. Malaria Journal 2014 13:182.

\section{Submit your next manuscript to BioMed Central and take full advantage of:}

- Convenient online submission

- Thorough peer review

- No space constraints or color figure charges

- Immediate publication on acceptance

- Inclusion in PubMed, CAS, Scopus and Google Scholar

- Research which is freely available for redistribution 